\title{
Determine the effectiveness of post-operative pain management of ultrasound guided transversus abdominis plane block vs open internal transversus abdominis plane block following abdominal hysterectomy a randomized controlled study
}

\author{
P Randombage ${ }^{a}$, S Hemapriya ${ }^{b}$, S Gnanarathna ${ }^{b}$
}

\begin{abstract}
Introduction: Abdominal hysterectomy is a common surgical procedure associated with considerable post-operative pain. The surgical outcomes are generally improved when pain control is optimized in the postoperative period. The transversus abdominis plane (TAP) block is an evolving regional anesthetic technique which provides analgesia to the skin, muscle and parietal peritoneal layers of anterior abdominal wall leading to reduction of post-operative pain.

Objectives: To compare the effectiveness in reducing postoperative pain between ultrasound guided TAP block, open internal TAP block and without TAP block in patients undergoing abdominal hysterectomy under general anaethesia.

Methods: Three-armed randomized case control prospective study conducted in Teaching Hospital Kandy from August 2016 to May 2017. Sixty six (66) patients scheduled and admitted for abdominal hysterectomy via supra- pubic transverse incision under general anaesthesia, aged between 40-60 years were included. Block randomization technique was applied to achieve the allocation concealment. There were 22 participants in each group of each arm. The Group 1 received USS guided TAP block, Group 2 open TAP block and Group 3 neither TAP block administered. The key data collected by a blinded observer at 12, 24 and 48 post-operative points were analgesic requirements and the analogue pain scale measurements of post-operative pain. These were compared in three groups. 95\% confidence interval and 0.05 probability cut off were used to determine statistical significance.

Results: The Mean age of the all participants was 51.98 years $(\mathrm{SD}=8.36)$ and length of the surgical incision ranged from $10 \mathrm{~cm}$ to $13 \mathrm{~cm}$. Mean weight of participants was $60.69 \mathrm{~kg}$ (SD - 7.0kg). Majority of the surgeries were completed in less than 45 minutes $(n=42: 63.6 \%)$. There was no significant difference in above three measurements in the three groups.

The difference in mean pain score in all 3 study groups were statistically significant at time points of 12,24 and 48 hours $(\mathrm{F}=15.45-12 \mathrm{H}: \mathrm{F}=12.63-24 \mathrm{H}: \mathrm{F}=7.67-48 \mathrm{H})$. The difference in mean Pethidine requirement in all 3 study groups were statistically significant at 3 time points of 12,24 and 48 hours $(F=20.71-12 \mathrm{H}: F=14.4-24 \mathrm{H}: \mathrm{F}=10.52-48 \mathrm{H})$. The difference in mean NSAID requirement in all 3 study groups at 24 - and 48 -hour study points studied were statistically significant $(\mathrm{F}=5.98-24 \mathrm{H}$ : $\mathrm{F}=8.07-48 \mathrm{H})$.

Conclusions: In abdominal hysterectomy the pain score, Pethidine and NSAID requirement was less, in participants who received an USS TAP block and an Open TAP block as a post-operative pain relief method when compared with participants who did not receive either. However, the data did not confirm that one TAP block is statistically superior to other. More detail experimental studies should be planned to evaluate the effectiveness of post-operative pain relief of TAP blocks during open abdominal hysterectomy and TAP blocks compared with existing post-operative pain relief protocols.
\end{abstract}

Key words: analgesics, hysterectomy, TAP blocks

Sri Lanka Journal of Obstetrics and Gynaecology 2020; 42: 76-86

DOI: http://doi.org/10.4038/sljog.v42i2.7944

a Senior Registrar in Obstertrics and Gynaecology, Colombo South Teaching Hospital, Kalubowila, Sri Lanka.

b Consultant Obstetrician and Gynaecologist, Teaching Hospital, Kandy, Sri Lanka.

Correspondence: PR, e-mail: prabathrandombage@gmail.com

D https://orcid.org/0000-0002-3576-9923

Received 21 $1^{\text {st }}$ March 2020

Accepted $1^{\text {st }}$ May 2020

This is an open-access article distributed under the terms of the Creative Commons Attribution 4.0 International License, which permits unrestricted use, distribution and reproduction in any medium provided the original author and source are credited. 


\section{Introduction}

The transversus abdominis plane (TAP) block is an evolving regional anesthetic technique which provides analgesia to the skin, muscle and parietal peritoneal layers of anterior abdominal wall leading to reduction of post-operative pain and improving quality of postoperative recovery ${ }^{1}$. Originally described as a blind technique the advent of ultrasound has made the method more popular. However, since the day of introduction nearly a decade ago, though many different methods have been introduced with low risks, TAP block still remains underutilized in clinical practice ${ }^{2,3}$. Among these methods, the low risk profile ultrasound guided TAP block which is on hands of anesthetists and open internal TAP block which is on surgeons' hands became most popular recently.

The TAP block was firstly introduced by Rafi in 2001 where he denoted it as "abdominal field block"4. Presently it is referred to as "direct TAP block", where the correct plane is entered through the lumbar triangle of petit, the surface in between lateral edge of external oblique muscle, lateral edge of latissimus dorsi muscle and superior surface of iliac crest.

An ultrasound guided approach (USS guided TAP block) introduced by Hebbard in 2007 became popular throughout the world rapidly ${ }^{5,6}$. It is done following applying an ultrasound scanner probe to the anterolateral abdominal wall and identifying the three muscle layers and once identified scanner probe moves poster lateral to lie across midaxillary line above the iliac crest? Block needle is then introduced anteriorly while real time ultrasonographic monitoring until reaching the correct tissue plane. This is also referred to as "posterior TAP block".

In the recent past surgeons too contributed to the TAP block, first described during laparoscopic surgery where the exact site of injecting was identified internally ${ }^{8}$. Thereafter the surgeons, intra operatively directly visualized the TAP approach. This is referred to as "open internal TAP block". This method avoids the risk of accidental intraperitoneal injection observed in the ultrasound guided TAP block.

\section{Methods}

This was a prospective double blinded randomized case control study of 66. Minimum sample size was calculated through WHO published Lwanga Lameshow equation. Participants undergoing abdominal hysterectomy under general anaethesia. The patients were allocated to three study arms with a group of participants in each. The study was conducted at ward 05, Teaching Hospital Kandy, from August 2016 to May 2017.

Sampling frame included patients scheduled and admitted for abdominal hysterectomy via supra pubic transverse incision, aged between 40-60 years, whom American Society of Anesthesiologists'(ASA) physical status between I-III during preoperative assessment conducted at anesthetic clinic or ward.

The patients with a history of drug allergy to local anesthetic agents, having local skin abnormalities at the site of introducing the TAP block like burned skin, local infection and inflammatory conditions were excluded from the study. The patients who had past pelvic surgeries with lower abdominal suprapubic incisions, diagnosed to have stage 3-4 endometriosis, pelvic inflammatory diseases and malignant conditions were excluded from the study due to high possibility of intraperitoneal adhesions impending surgical difficulties. Also, the patients with diabetes were excluded due to risk of neuropathy. All emergency surgeries were excluded.

The Study Group of 66 participants were selected at the gynaecology clinics according to the above inclusion and exclusion criteria. Block randomization was carried out by computer-generated random numbers. Randomization was done by the supervisor to keep the primary investigator blinded and allocated to the 3 Arms with a Group in each arm.

The Group 1 of 22 participants received "USS guided TAP block" immediately following closure of the skin before recovery. The anesthetic agent was injected $20 \mathrm{ml}$ $0.25 \%$ bupivacaine per side under USS guidance. The 22 participants in Group 2 received "Open internal TAP block" just before the closure of rectus sheath by lifting the anterior abdominal wall with a retractor and injecting the anesthetic agent $20 \mathrm{ml}$ 0.25\% Bupivacaine per side under direct visualization following intraperitoneal palpation of inferior epigastric artery and approaching lateral to the artery.

The comparison group of 22 participants received "no TAP block” but received one dose of intramuscular 
Pethidine 50-75mg in the immediate post-operative period. Same dose of Pethidine administered to participants in USS TAP block and Open TAP Block to alleviate intraperitoneal visceral pain. Simple analgesics like paracetamol and diclofenac sodium suppository 100 mg 12 hourly were offered to all participants in three groups freely, according to unit policy and the data also documented in data collection form.

Data was collected on to a specially designed data collection form and saved on to an electronic data base simultaneously. Demographic data including age, height, weight, size of the scar and duration of surgery in all three groups were compared for satisfactory randomization using ANOVA and ' $t$ ' test. 0.05 probability cut off level was applied to determine statistical significance. No post hoc analysis was conducted to determine specific differences. As the post-operative Pethidine requirement is a parametric continuous variable it will be presented as means and 95\% CI. If these are normally distributed, comparing the means of continuous variable in Group 1 and 2 were analysed by the ' $t$ ' test. Pain assessment was done by using visual analogue pain scale. The Visual Scale was presented to participants at each selected time point (12, 24, and 48 hours after surgery). The participants' pain measurement was used for statistical analysis. The range of the visual pain scale ranged from 1 to 10 and was analyzed as a continuous variable. Post-operative Pethidine requirements of participants in all three groups at 12, 24, 48 hours were analysed. All above mentioned statistical analyses were performed using standard statistical techniques available in SPSS version 25.0. Written informed consent was obtained from all the participants prior to the study. The study was approved by the Ethics Committee of the Faculty of Medical Sciences, University of Sri Jayewardenepura and Ethics Review Committee of Teaching Hospital, Kandy.

\section{Results}

Age of the study participants ranged from 38 years to 71 years. Majority of the study participants were in the 46-55 years age group (Mean - 51.98 years: SD 8.36 years). Body weight of the study participants ranged from $47 \mathrm{~kg}$ to $78 \mathrm{~kg}$. Majority of the study participants were in the $61 \mathrm{~kg}$ to $78 \mathrm{~kg}$ weight group (Mean - $60.69 \mathrm{~kg}$ : SD - 7.0kg). BMI of the study participants ranged from $19.28 \mathrm{kgm}^{-2}$ to $34.69 \mathrm{kgm}^{-2}$ (Mean - $26.21 \mathrm{kgm}^{-2}$ : SD - $3.54 \mathrm{kgm}^{-2}$ ) (Table 1). There was no significant difference in the participants' age, weight, BMI and ASA in the three groups (Table 2).

Table 1. Distribution of age, weight and the BMI of the study participants

\begin{tabular}{|l|c|c|}
\hline & Number (N) & Percentage (\%) \\
\hline Age & & \\
$<45$ years & 11 & 16.7 \\
$46-55$ years & 36 & 54.5 \\
$56-65$ years & 14 & 21.2 \\
$=>66$ years & 5 & 7.6 \\
\hline Weight & & \\
$<50 \mathrm{~kg}$ & 9 & 13.6 \\
$51-60 \mathrm{~kg}$ & 21 & 31.8 \\
$61-70 \mathrm{~kg}$ & 31 & 47.0 \\
$=>71 \mathrm{~kg}$ & 5 & 7.6 \\
\hline BMI & & \\
$<20$ & 3 & 4.5 \\
$20.1-24.9$ & 19 & 28.8 \\
$25-29.9$ & 35 & 53.0 \\
$=>30$ & 9 & 13.6 \\
\hline Total & $\mathbf{6 6}$ & $\mathbf{1 0 0}$ \\
\hline
\end{tabular}


Table 2. Comparison of mean values of age, weight and body mass index

\begin{tabular}{|l|c|c|c|c|c|}
\hline & Group 1 & Group 2 & Group 3 & F value \\
\hline Age & $\begin{array}{c}\text { USS TAP } \\
(\mathbf{n = 2 2 )}\end{array}$ & $\begin{array}{c}\text { Open TAP } \\
\mathbf{( n = 2 2 )}\end{array}$ & $\begin{array}{c}\text { No TAP } \\
\mathbf{( n = 2 2 )}\end{array}$ & & \\
Weight & 52.59 & 53.05 & 50.32 & 0.666 & 0.51 \\
BMI & 62.18 & 60.77 & 59.13 & .921 & .40 \\
& 26.91 & 25.52 & 26.21 & .837 & .43 \\
\hline
\end{tabular}

'F' - ANOVA; Statistical significance level at $P=0.05$

There were four surgical incision sizes and minimum incision size was $10 \mathrm{~cm}$ and maximum incision size was $13 \mathrm{~cm}$. Incision size of majority of the surgeries were between $11 \mathrm{~cm}$ to $12 \mathrm{~cm}(\mathrm{~N}=45: 68 \%)$. There was no statistically significant difference in three study groups with regard to the length of surgical incision $(\mathrm{F}=0.244: \mathrm{p}=0.784)$

Minimum time taken for a surgery was 40 minutes and maximum time was recorded as 55 minutes (Mean - 45.61 minutes: SD - 3.89). There was no statistically significant difference in three study groups with regard to the duration of surgery $(\mathrm{F}=0.584$ : $\mathrm{p}=0.561$ ).

The difference in mean pain score in all 3 study groups at time points of 12, 24 and 48 hours were statistically significant $(\mathrm{F}=15.45-12 \mathrm{H}$ : $\mathrm{F}=12.63-24 \mathrm{H}$ : $\mathrm{F}=7.67-48 \mathrm{H})$ (Table 4). Minimum pain score at 12 hours of surgery was recorded in USS TAP block group and the maximum mean pain score was recorded in no TAP block group and difference was significant $(\mathrm{F}=15.41$ : $\mathrm{P}<0.001$ ) (Table 4). Minimum pain at 24 hours of surgery was in open TAP block group and maximum pain score in USS TAP block group and difference was significant $(\mathrm{F}=12.63$ : $\mathrm{P}<0.001)$ (Table 4). Minimum pain score at 48 hours of surgery was observed in USS TAP block group and the maximum mean pain score in open TAP block group and the difference was statistically significant $(\mathrm{F}=7.67$ : $\mathrm{P}<0.001$ ) (Table 4).

The difference in mean Pethidine requirement in all three study Groups were statistically significant at 3 time points of 12, 24 and 48 hours $(\mathrm{F}=20.71-12 \mathrm{H}$ : $\mathrm{F}=14.4-24 \mathrm{H}$ : With relevance to all time periods, Pethidine requirement of the USS TAP block was less than in no TAP block group the difference was significant $(\mathrm{t}=5.73-12 \mathrm{H}: \mathrm{t}=5.28-24 \mathrm{H}: \mathrm{t}=4.41-48 \mathrm{H}$ : $\mathrm{P}<0.001$ ) (Table 6). At all time periods, Pethidine requirement of open TAP block group was less than in no TAP block group and the difference was significant. ( $\mathrm{t}=6.68-12 \mathrm{H}: \mathrm{t}=4.50-24 \mathrm{H}: \mathrm{t}=3.61-48 \mathrm{H}: \mathrm{P}<0.001)$ (Table 5).

Table 3. Distribution of size of the incision and duration of surgery

\begin{tabular}{|c|c|c|c|}
\hline & & Frequency (N) & Percentage (\%) \\
\hline Size of incision & $\begin{array}{l}10 \mathrm{~cm}-10.9 \mathrm{~cm} \\
11 \mathrm{~cm}-11.9 \mathrm{~cm} \\
12 \mathrm{~cm}-12.9 \mathrm{~cm} \\
13 \mathrm{~cm}-13.9 \mathrm{~cm}\end{array}$ & $\begin{array}{c}18 \\
22 \\
23 \\
3\end{array}$ & $\begin{array}{c}27.3 \\
33.3 \\
34.8 \\
4.5\end{array}$ \\
\hline Duration of surgery & $\begin{array}{l}<45 \text { minutes } \\
=>46 \text { minutes }\end{array}$ & $\begin{array}{l}42 \\
24\end{array}$ & $\begin{array}{l}63.6 \\
36.4\end{array}$ \\
\hline
\end{tabular}


Table 4. Comparison of pain score among study participants

\begin{tabular}{|c|c|c|c|c|c|}
\hline \multirow{2}{*}{$\begin{array}{c}\text { Post-operative } \\
\text { time }\end{array}$} & \multicolumn{3}{|c|}{ Mean pain score } & \multirow[t]{2}{*}{$\mathbf{F}$} & \multirow[t]{2}{*}{$P$ value } \\
\hline & $\begin{array}{c}\text { Group } 1 \\
\text { USS TAP } \\
(n=22)\end{array}$ & $\begin{array}{c}\text { Group } 2 \\
\text { Open TAP } \\
(n=22)\end{array}$ & $\begin{array}{c}\text { Group } 3 \\
\text { No TAP } \\
(n=22)\end{array}$ & & \\
\hline $12 \mathrm{H}$ & 7.00 & 7.32 & 7.86 & 15.41 & $<0.001$ \\
\hline $24 \mathrm{H}$ & 6.32 & 6.23 & 5.59 & 12.63 & $<0.001$ \\
\hline $48 \mathrm{H}$ & 5.50 & 7.36 & 6.14 & 7.67 & $<0.001$ \\
\hline
\end{tabular}

' $F$ ' - ANOVA; Statistical significance at $P=0.05$

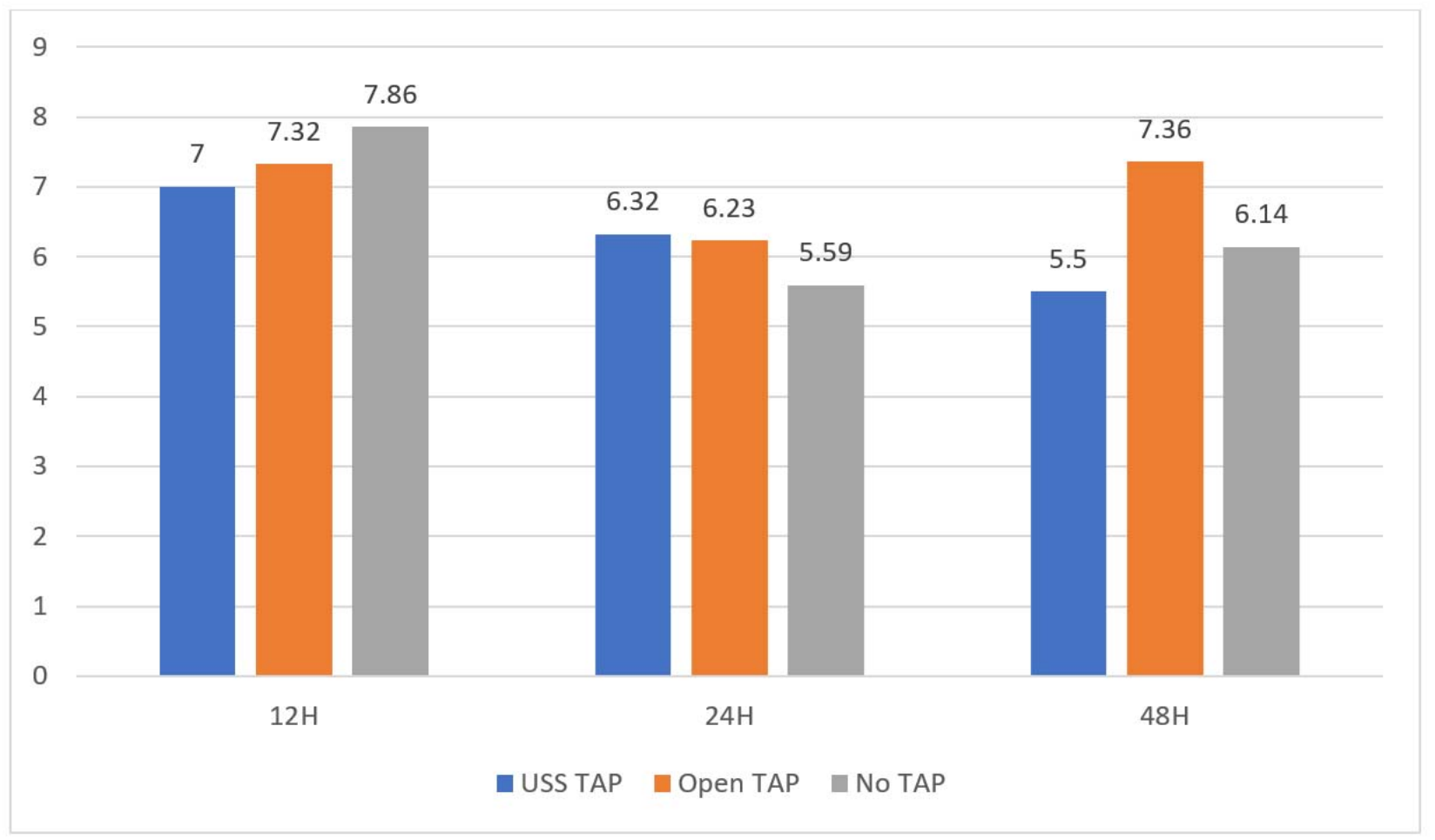

Figure 1. Pain score in post-operative period.

The Pethidine requirement at point of 12 hours of the USS TAP block was higher than the Pethidine requirement of an open TAP block group. At time point of 24 hours and 48 hours, Pethidine requirement of open TAP block group was higher than the USS guided TAP block group. However, a significant difference was not observed at any time points between the Group 1 who received an USS guided TAP block group and Group 2 who received an open TAP block group. ( $\mathrm{t}=0.395$ 12H: $\mathrm{t}=0.531-24 \mathrm{H}: \mathrm{t}=0.769-48 \mathrm{H}: \mathrm{P}>0.446$ ) (Table 5). 
Table 5. Difference of means of Pethidine requirements between study groups

\begin{tabular}{|c|c|c|c|c|}
\hline \multirow[b]{2}{*}{ Post-Operative time } & \multicolumn{2}{|c|}{ Pethidine requirements } & \multirow[b]{2}{*}{$\mathbf{T}$} & \multirow[b]{2}{*}{ P-Value } \\
\hline & $\begin{array}{c}\text { Group } 1 \\
\text { USS TAP } \\
(n=22)\end{array}$ & $\begin{array}{c}\text { Group } 3 \\
\text { No TAP } \\
(n=22)\end{array}$ & & \\
\hline $12 \mathrm{H}$ & 1.54 & 2.29 & 5.73 & $<0.001$ \\
\hline $24 \mathrm{H}$ & 2.56 & 3.36 & 5.28 & $<0.001$ \\
\hline \multirow[t]{2}{*}{$48 \mathrm{H}$} & 4.01 & 5.26 & 4.41 & $<0.001$ \\
\hline & $\begin{array}{c}\text { Group } 2 \\
\text { USS TAP } \\
(\mathrm{n}=22)\end{array}$ & $\begin{array}{c}\text { Group } 3 \\
\text { No TAP } \\
(n=22)\end{array}$ & $\mathbf{T}$ & P-Value \\
\hline $12 \mathrm{H}$ & 1.48 & 2.29 & 6.68 & $<0.001$ \\
\hline $24 \mathrm{H}$ & 2.65 & 3.36 & 4.50 & $<0.001$ \\
\hline \multirow[t]{2}{*}{$48 \mathrm{H}$} & 4.24 & 5.26 & 3.61 & 0.001 \\
\hline & $\begin{array}{c}\text { Group } 1 \\
\text { USS TAP } \\
(n=22)\end{array}$ & $\begin{array}{r}\text { Group } 2 \\
\text { No TAP } \\
(n=22)\end{array}$ & $\mathbf{T}$ & P-Value \\
\hline $12 \mathrm{H}$ & 1.54 & 1.48 & 0.395 & 0.695 \\
\hline $24 \mathrm{H}$ & 2.56 & 2.65 & 0.531 & 0.598 \\
\hline $48 \mathrm{H}$ & 4.01 & 4.24 & 0.769 & 0.446 \\
\hline
\end{tabular}

Statistical significance at $P=0.05$

The difference in mean NSAID requirement in all 3 study Groups at 24 and 48 hour study points were statistically significant $(\mathrm{F}=5.98-24 \mathrm{H}: \mathrm{F}=8.07-48 \mathrm{H})$ (Table 6). At 24 and 48 hour points the NSAID requirement in USS TAP block group and Open TAP block group were less than no TAP group (Table 6). At postoperative 24 hours the minimum NSAID requirement was in USS TAP block group and maximum in no TAP group. At 48 hours the minimum NSAID requirement was in open block group and maximum in USS guided group. Mean requirement of NSAAID dosage was less in Open TAP group compared to USS guided TAP block group in $24 \mathrm{H}$ following surgery, but the finding was not statistically significant $(\mathrm{p}=0.37$ ). 
Table 6. Distribution of mean analgesic requirements in all study groups

\begin{tabular}{|c|c|c|c|c|c|}
\hline \multirow[t]{2}{*}{$\begin{array}{c}\text { Post-operative } \\
\text { time }\end{array}$} & \multicolumn{3}{|c|}{$\begin{array}{l}\text { Mean analgesic } \\
\text { requirements }\end{array}$} & \multirow[t]{2}{*}{$\mathbf{F}$} & \multirow[t]{2}{*}{$P$ value } \\
\hline & $\begin{array}{c}\text { Group } 1 \\
\text { USS TAP } \\
(n=22)\end{array}$ & $\begin{array}{c}\text { Group } 2 \\
\text { Open TAP } \\
(n=22)\end{array}$ & $\begin{array}{c}\text { Group } 3 \\
\text { NoTAP } \\
(n=22)\end{array}$ & & \\
\hline \multicolumn{6}{|l|}{ NSAID } \\
\hline $24 \mathrm{H}$ & 145.45 & 159.09 & 190.91 & 5.98 & 0.004 \\
\hline $48 \mathrm{H}$ & 254.54 & 240.91 & 329.54 & 8.07 & 0.001 \\
\hline \multicolumn{6}{|l|}{ Pethidine } \\
\hline $12 \mathrm{H}$ & 1.54 & 1.48 & 2.29 & 20.71 & $<0.001$ \\
\hline $24 \mathrm{H}$ & 2.56 & 2.65 & 3.36 & 14.4 & $<0.001$ \\
\hline $48 \mathrm{H}$ & 4.01 & 4.24 & 2.29 & 10.52 & $<0.001$ \\
\hline
\end{tabular}

'F' - ANOVA; Statistical significance at $P=0.05$

\section{Discussion}

In all three study groups, an increase in the Pethidine analgesic requirement was observed with increasing post-operative time points. The manner of associating effects of Pethidine with pain sensation and time was not addressed in the study design. Therefore, it is more complicated to generate a clear conclusion when pain relief and usage of Pethidine analgesic are combined together. The Pethidine requirement at post-operative points of 12, 24 and 48 hours in USS TAP and open TAP groups was significantly less than the no TAP group. However a significant difference of Pethidine requirement was not observed between USS TAP group and open TAP group. Therefore, either open or USS guided TAP block reduce the usage of Pethidine during the post-operative period.

When USS guided and Open TAP were combined with diclofenac sodium suppository $100 \mathrm{mg} 12$ hourly) as an analgesic, the requirement of NSAID of participants in USS TAP group and open TAP group was less than in no TAP group, demonstrating a better pain relief in
TAP Groups. The NSAID requirement in USS TAP group was less than in open TAP group at 24 hours. But at 48-hour point situation this altered inversely. However, the difference was not statistically significant in either. Therefore, it is necessary to study this matter further, using larger sample sizes.

As Nigma et al, has described in 2017, it is possible to reduce Morphine requirement during the post-operative period by administration of TAP block during the surgery. Also it is possible to delay the first analgesic request during post-operative period ${ }^{25}$. According to a systematic review conducted by Vanessa Bacal in 2018, fourteen studies which included 855 participants demonstrated that there was a significant reduction of post-operative pain during first 48 hours among patients who received TAP block ${ }^{25}$.

All these fourteen studies which were included in to the analysis conducted by Bacal et al had used the visual pain scale which was used during the present study. Also Bacal et al declares that, it is possible to 
significantly reduce the need of administrating post operative analgesics by providing TAP block ${ }^{25}$.

This significant post-operative pain relief which can be achieved by TAP block was confirmed by Chang et al in $2018^{26}$ and Chistian et al in $2018^{27}$. Also Bhaleta et al in 2018 had demonstrated that this TAP block can be used for laparoscopic gynecological surgeries as well ${ }^{28}$.

When practical feasibility is considered, it is more suitable to promote open TAP block as a standard pain relief method because it can be administered during surgery without contributions from additional human resources.

A high incidence of unwanted side effects has been reported in many studies with administration of opioid analgesics including Pethidine. However, this area was not addressed in the study. These opioid analgesics such as Pethidine are prescribed combined with antiemetics to minimize such side effects. On the other hand, addiction up to a certain extent is also expected with opioids. Open TAP block pain relief method, which required less amount of Pethidine than USS TAP and No TAP, as per study results, may be recommended as a safer and effective pain relief intervention.

In the study sample, majority of the surgeries were done through a surgical incision extending less than $11 \mathrm{~cm}$ and completed in less than 45 minutes. These two factors directly affect the severity of pain following surgery. There is a higher probability of expecting a significant difference between open TAP block method and the USS guided TAP block method though not addressed in the study. If a comparative analysis is conducted along with these two factors in the future, it may be apparent that findings obtained during this study should be further analyzed, because there could be many biological and socio-cultural factors which associate with pain sensation and relief techniques

An effective pain relief protocol is a medical management strategy which will enhance the post-operative recovery phase with less pain, shorter hospital stay, minimum cost and resource utilization. Therefore, further studies with expanded settings and study samples may be required to confirm above advantages in TAP blocks, especially open TAP block. As per findings gynecological management guidelines may be amended.
Several methodological limitations which occur in RCT were observed during the present study. In selecting the study sample, had to satisfy with the minimum required sample size, which appeared disadvantageous while studying a variable such as pain. Pain is a biological parameter which can be associated with many confounding factors, such as socio-cultural factors, educational status, age and weight of the study participants. It was not possible to apply methods such as matching and restrictions in order to equally distribute the effects of confounding factors during selection of the study sample. As a result, a selection bias was generated up to a certain extent, which created an effect on the internal validity of the study findings.

Visual analogue scale used for pain assessment extracts a highly subjective assessment. Since the study participants were elderly, it is possible to expect an association between pain assessment and their medical comorbidities. In addition, it is possible to expect a less pain bearing capacity than young females. When all above factors are considered, it is possible to expect an information error when conducting a pain assessment with a visual analogue scale. It was not possible to recruit a larger number of participants in order to minimize such information error. If it was possible to validate the visual pain analogue tool in participants prior to application, more accurate pain assessment information could have been obtained.

In the current study, main study variable and outcome was post-surgical pain. Pain relief is a medically and ethically sensitive issue and when patient requests pain relieving agents, health care delivery team generally attempts to provide possible pain relief to the patient. When conducting a study, due to practical and ethical reasons it is difficult to apply restrictions on pain relief requests. As a result, there is a possibility that the study findings may not represent the true picture, which appears to be an inevitable limitation.

Many unpleasant side effects are expected with opioid analgesics, including nausea and vomiting. Hence there is a possibility of not requesting opioid analgesics as pain relief medication. This situation also creates a limitation which will not reveal the true picture of Pethidine requirement.

In the present study, 3 groups were compared with each other. As the dependent variables such as visual 
pain scale, dosses of analgesic requirement of this study were in a continuous scale and the exposure variable (Type of peri operative analgesia: TAP Block) was in a categorical scale, the most suitable statistical test for analysis of the findings was the ANOVA test. But there were limited inter group comparisons in the present study. There were possibilities of eliciting more detailed findings, if objectives were developed in favor of comparing separate two groups. This fact should be carefully addressed in future studies.

When further studies are planned on this subject, attention should be on using more heterogeneous and homogenous samples. Post-operative pain relief with relevance to open abdominal hysterectomy was considered during the present study. As most of the study participants were in their post-menopausal age group, factors associated with their pain sensation and pain management could differ from another none specific group. As a result, external validity of the findings obtained from such a sample could be reduced up to a certain extent. Therefore, most suitable method is using a study sample with relatively larger number of study participants and conduct several studies at different study settings. It will be possible to overcome this limitation by conducting systematic analysis of the findings of above-mentioned studies and it will help to obtain a more externally validated conclusion.

There is a clearly identified potentiality of reducing the post-operative analgesic requirement by administrating Open or USS guided TAP blocks. As per findings and reasons stated above such as cost effectiveness and minimum resource requirement. It appears that the open TAP is better than USS guided TAP. Application of TAP blocks should be compared with existing postoperative pain relief strategies. It will help to generate more cost effective strategic interventional combination for post-operative pain management in abdominal hysterectomy.

\section{Acknowledgements}

The director and the supportive staff attached to the gynaecology and obstetrics unit as well as the staff of operation theatre of Teaching Hospital Kandy. Dr. S Kiriwaththuduwa, Consultant Anesthetist, Teaching Hospital Kandy.
Conflicts of interests: No conflicts of interests to be declared.

\section{References}

1. Charlton S, Cyna AM, Middleton P, Grifths JD. Perioperative transversus abdominis plane (TAP) blocks for analgesia after abdominal surgery. Cochrane Database of Systematic Reviews 2010; 8, Article ID CD007705.

2. Kearns RJ, Young SJ. Transversus abdominis plane blocks; a national survey of techniques used by UK obstetric anaesthetists. International Journal of Obstetric Anesthesia. 2011; 20(1): 103-4.

3. Petersen LI, Mathiesen O, Torup H, Dahl JB. The transversus abdominis plane block: a valuable option for postoperative analgesia? A topical review. Acta Anaesthesiol Scand [Internet]. 2010; 54(5): 529-35.

Available from: https://onlinelibrary.wiley.com/doi/ abs/10.1111/j.1399-6576.2010.02215.x

4. Rafi AN. Abdominal field block: a new approach via the lumbar triangle. Anaesthesia. 2001; 56(10): 1024-26.

5. Hebbard P, Fujiwara Y, Shibata Y, Royse C. Ultrasound-guided transversus abdominis plane (TAP) block. Anaesthesia and Intensive Care. 2007; 35(4): 616-17.

6. Le Roux A, Cognet F, Le Hetet H, Vautier P, Aveline C, Tison C, et al. Comparison between ultrasound-guided transversus abdominis plane and conventional ilioinguinal/iliohypogastric nerve blocks for day-case open inguinal hernia repair. BJA Br J Anaesth [Internet]. 2010; 106(3): 380-6.

Available from:https://doi.org/10.1093/bja/aeq363

7. Ra YS, Kim CH, Lee GY, Han JI. The analgesic effect of the ultrasound-guided transverse abdominis plane block after laparoscopic cholecystectomy. Korean J Anesthesiol [Internet]. 2010/04/28. 2010 Apr;58(4):362-8.

Available from: https://www.ncbi.nlm.nih.gov/ pubmed/20508793

8. Chetwood A, Agrawal S, Hrouda D, Doyle P. Laparo-scopic assisted transversus abdominis plane block: a novel insertion technique during laparoscopic nephrectomy. Anaesthesia. 2011; 66(4): 317-18. 
9. Kadam R V, Field JB. Ultrasound-guided continuous transverse abdominis plane block for abdominal surgery. J Anaesthesiol Clin Pharmacol [Internet]. 2011; 27(3): 333-6.

Available from:https://www.ncbi.nlm.nih.gov/ pubmed/21897502

10. Shin H-J, Kim ST, Yim KH, Lee HS, Sim JH, Shin YD. Preemptive analgesic efficacy of ultrasoundguided transversus abdominis plane block in patients undergoing gynecologic surgery via a transverse lower abdominal skin incision. Korean J Anesthesiol [Internet]. 2011/11/23. 2011; 61(5): 413-8. Available from: https://www.ncbi.nlm.nih.gov/pubmed/ 22148091

11. Bhatia N, Arora S, Jyotna W, Kaur G. Comparison of posterior and subcostal approaches to ultrasound-guided transverse abdominis plane block for postoperative analgesia in laparoscopic cholecystectomy. J Clin Anesth [Internet]. 2014; 26(4): 294-9.

Availablefrom: http://www.sciencedirect.com/ science/article/pii/S0952818014000567

12. Brady RR, Ventham NT, Roberts DM, Graham C, Daniel T. Open transversus abdominis plane block and analgesic requirements in patients following right hemicolectomy. Ann R Coll Surg Engl [Internet]. 2012; 94(5): 327-30.

Available from: https://doi.org/10.1308/ $003588412 X 13171221589856$

13. Bharti N, Kumar P, Bala I, Gupta V. The eficacy of a novel approach to transversus abdominis plane block for postoperative analgesia after colorectal surgery. Anesthesia and Analgesia. 2011; 112(6): 1504-8.

14. Owen DJ, Harrod I, Ford J, Luckas M, Gudimetla $\mathrm{V}$. The surgical transversus abdominis plane block - a novel approach for performing an established technique. British Journal of Obstetrics and Gynaecology. 2011; 118(1): 24-27.

15. Kehlet H, Holte K. Effect of postoperative analgesia on surgical outcome. Br J Anaesth. 2001; 87(1): 62-72.

16. McDonnell JG, O’Donnell B, Curley G, Heffernan A, Power C, Laffey JG. The analgesic efficacy of transversus abdominis plane block after abdominal surgery: a prospective randomized controlled trial. Anesth Analg. 2007; 104: 193-7.
17. McDonnell JG, Curley G, Carney J, Benton A, Costello J, Maharaj CH, Laffey JG. The analgesic efficacy of transversus abdominis plane block after cesarean delivery: a randomized controlled trial. Anesth Analg. 2008; 106: 186-91.

18. Mc Donnel JG, Carney J, Ochana A, Bhinder R, Laffey JG. The analgesic efficacy of transversus abdominis plane block after hysterectomies: a randomized controlled trial. International Anesthesia Research Society. 2008; 107(6): 2056-60.

19. Carney J, McDonnell JG, Ochana A, Bhinder R, Laffey JG. The Transversus Abdominis Plane Block Provides Effective Postoperative Analgesia in Patients Undergoing Total Abdominal Hysterectomy. Anesth Analg [Internet]. 2008; 107(6). Available from: https://journals.lww.com/ anesthesiaanalgesia/Fulltext/2008/12000/ The_Transversus_Abdominis_Plane_Block_Provides. 46.aspx

20. Gharaei H, Imani F, Almasi F, Solimani M. The Effect of Ultrasound-guided TAPB on Pain Management after Total Abdominal Hysterectomy. Korean J Pain. 2013; 26( 4): 374-8.

21. Wijewardana MG, Pathiraja R, Jayawardane MA. The Analgesic Efficacy of Transversus Abdominis Plane (TAP) Block after Total Abdominal Hysterectomy: A Randomized Controlled Trial. Sri Lanka Journal of Obstetrics and Gynaecology. 2014 March: 5-10.

22. Kasiulevicius V, Sapoka V, Filipaviciute R. Sample size calculation in epidemiological studies. Gerontologija 2006; 7(4): 225-31.

23. Ma N, Duncan JK, Scarfe AJ, Schuchman S, Cameron AL. Clinical safety and effectiveness of transversus abdominis plane (TAP) block in postoperative analgesia: a systematic review and metaanalysis. J. Anesth. 2017; 31(3): 432-5. [Pub Med] [Google Scholar]

24. Analgesic effect of ultrasound-guided transversus abdominis plane block after total abdominal hysterectomy: a randomized, double-blind, placebo-controlled trial. Rojskjaer JO, Gade E, Kiel LB, et al. Acta Obstet Gynecol Scand. 2015; 94: 274-8. [PubMed] [Google Scholar]

25. Transversus abdominis plane block for post hysterectomy pain: a systematic review and metaanalysis. Bacal V, Rana U, McIsaac DI, Chen I. J Minim Invasive Gynecol. 2018 [PubMed] [Google Scholar. 
26. Chang H, Rimel BJ, Andrew J Li, Ilana Cass, Beth Y, Karlan, Walsh C. Ultrasound guided transversus abdominis plane (TAP) block utilization in multimodal pain management after open gynecologic surgery. Gynecol Oncol Rep. 2018; 26: $75-7$.

27. Dai C, Zhang K, Huang J. The Efficacy of Transversus Abdominis Plane Block for Abdominal Hysterectomy Post-operative Analgesia. Cureus 2018; 10(8): e3131.
28. Bhakta A, Glotzer O, Ata A, Tafen M, Stain SC, Singh PT. Analgesic efficacy of laparoscopicguided transverse abdominis plane block using liposomal bupivacaine in bariatric surgery. Am J Surg. 2018; 215: 643-6. [Pub Med] [Google Scholar]

29. Mathew P, Aggarawal N, Kumari K, et al. Quality of recovery and analgesia after $\mathrm{AH}$ under general anaesthesia; RCT TAP vs Epidural and Paracetamol. J of Clinical Anaesthesiology and Pharmacology. 2020; 170-8. 